\title{
PKA, Caspase 1 and HSP40 Induced Apoptosis under Fungi
}

\section{Starvation}

\author{
Tobiloba Sojinrin¹, Kangze Liuํㅜ, Daxiang Cui ${ }^{2}$, James Curtin ${ }^{1}$ and \\ Furong $\operatorname{Tian}^{1 *}$ \\ ${ }^{1}$ College of Sciences and Health, Technological University Dublin, Ireland \\ 2Department of Instrument Science and Engineering, National Center for \\ Translational Medicine, Shanghai Jiao tong university, PR China
}

Research Article

Volume 4 Issue 2

Received Date: April 07, 2019

Published Date: April 30, 2019

DOI: $10.23880 /$ act-16000154

*Corresponding author: Furong Tian, School of Food Science and Environmental Health, College of Sciences and Health, Technological University Dublin, Cathal Brugha Street, Dublin 1, Ireland, Tel: 0035314047543; Email: furong.tian@dit.ie

\section{Abstract}

To investigate the influence of starvation on the biochemical response of Aspergillus niger. The biochemical impact of starvation was determined by morphological observation, immunofluorescent analysis, High-performance liquid chromatography (HPLC) and western blot over 8 days. Results showed that starvation can inhibit fungi survival rate in a time-dependent manner. A. niger exhibited active responses to starvation such as secretion of some $40 \mathrm{kDa}$ proteins to manage changes in water balance. Conidiophores disintegrated from lack of nutrient. The immunofluorescent analysis demonstrated elevated ROS accumulation in starved cells $(\mathrm{P}<0.001)$. The fluorescent microscopy of the TUNEL (terminal deoxynucleotidyl transferase dUTP nick end labelling) staining showed positive in the starved fungi. The mitochondrial stains revealed that the fluorescence emitted by the normal fungi was higher than the starving ones. Western blot analysis showed that starvation can induce up-regulation expression of cell cycle-associated proteins such as PKA, Caspase 1 and Heat Shock Protein 40 (HSP40). These results suggest that up regulation of apoptosis-associated protein may contribute to fungi apoptosis. In conclusion, starvations can active PKA, Caspase 1 and HSP40 protein to inhibit $A$. niger growth by inducing cell apoptosis.

Keywords: Aspergillus niger; Starvation; Apoptosis; PKA; Caspase 1; Heat Shock Protein 40

\section{Introduction}

Managing changes in water balance is a fundamental challenge for fungi in most environments. For survival in yeasts and fungi, starvation has been shown to depend on the nature of the missing nutrients. The missing nutrients of carbon, phosphate and nitrogen, amino acids or other metabolites can cause fungi death [1]. Apoptosis can be induced by aging or starvation. Apoptosis is cellular death that involves the active participation of the cell through the activation of a discrete signalling pathway(s) and has been an area of intensive study in multi-cellular organisms for many years. In animals, the mitochondrion integrates diverse cellular stress signals and initiates the death execution pathway, and studies indicate a similar involvement for mitochondria in regulating apoptosis in plants [2]. During the past decade, evidence of apoptosis 
has been obtained in both yeast and some filamentous fungi [3,4]. Amphothericin B, Hydrogen peroxide, Farnesol, Sphingoid long-chain bases and Antifungal protein PAF induced apoptosis have been studied in the area of externalization of phosphatidylserine, release of cytochrome $c$, involvement of cysteine proteases, and the presence of mitochondrial-signalling pathways. However, the mechanism of the cell death by starvation response is not clear [5-9].

ROS are important signalling molecules that induce several pathways [10]. During heat, the fusion hyphae undergo a series of apoptosis-associated morphological changes, including cytoplasm condensation, vacuolization, and shrinkage of the plasma membrane [11]. Several factors that control various molecular pathways (e.g. respiration, ROS production, mitochondrial DNA stability, dietary restriction, copper metabolism, translation fidelity, mitochondrial protein import and mitochondrial dynamics) are involved in lifespan control in fungus [1214].

Until recently, it had been assumed that apoptosis evolved only with the evolution of multi-cellularity. However, it has been discovered that apoptosis inducing proteins from mammalian cells such as $B A X$ could induce death with an apoptotic phenotype when expressed in the yeast Saccharomyces cerevisiae, and that this could be prevented by the simultaneous expression of the antiapoptotic mammalian protein BCL-2 (B-cell lymphoma-2). An interact between BCL-2/BCL-XL (B-cell lymphomaextra-large) has been reported in regulated apoptosis [15]. The caspase-like proteins have been found in C. elegans, Drosophila, zebrafish and mammals to involve apoptosis [16]. But many of the cell-death regulators that have been characterized in humans, worms and flies are absent from the fungi, indicating that fungi probably use other regulators to control this process. Fungi lack biochemical homologues of caspases, aspartate-specific cysteine proteases that are among the main players in mammalian apoptosis. In addition, although homologues of BCL-2 family members - which function as inducers (proapoptotic) or inhibitors (anti-apoptotic) of apoptosis have not, as yet, been identified in fungi, heterologous overexpression of the corresponding genes specifically affects apoptosis [17-19]. Increased PKA led to inflammation-independent activation of caspase-1. Caspase-1 plays a prominent role in inflammatory responses and the regulation of apoptosis of various tumour cells $[10,11]$.

Aspergillus niger will be incubated in the water without additional nutrition for serial of 8 days. The fungi growth is counted on the agar plates to investigate fungi survival rate in a time-dependent manner. Fungi morphology will be observed under light microscopy. The immunofluorescent analysis will be performed to demonstrate ROS accumulation. TUNEL (terminal deoxynucleotidyl transferase dUTP nick end labelling) and mitochondrial staining will be studied under fluorescence microscopy. Protein separation will be conducted to define the apoptosis related protein. Different pore sizes of filter such as $10 \mathrm{kDa}, 30 \mathrm{kDa}$ and 50 $\mathrm{kDa}$ will be used to separate the proteins of different size ranges after fungi starvation. HPLC will be employed to identify differences among different filtrations. Several proteins with size of $40 \mathrm{kDa}$, such as, PKA, Caspase 1 and Heat Shock Protein 40 (HSP40) will be semi quantified by western blot to evaluate protein expression.

\section{Materials and Methods}

A. niger fungal strain was supplied by Blades Biological Ltd. $100 \mu \mathrm{l}$ of re-suspended liquid was spread and incubated in a sterile container for inoculation on Sabouraud dextrose agar (SDA) at $25{ }^{\circ} \mathrm{C}$ for 5 days. Fungi were harvested in the sterile ultrapure deionized water and centrifuged at $8,720 \mathrm{~g}$ for 10 minutes. The fungi pellet was washed twice with sterile ultrapure deionized water. The pellet was re-suspended in sterile ultrapure deionized water. Re-suspended liquids, at a concentration of $1-100 \mathrm{CFU} / \mathrm{mL}$, were prepared. The A. niger colonies were counted following the experimental procedure $[20,22]$.

\section{Preparation of Fungi Cultures on Potato Dextrose Agar (PDA) Plates}

Culture slant of $A$. niger was ordered from Blades Biological Ltd. 39g of PDA agar was weighed out (alternatively $62 \mathrm{~g}$ of SDA agar could also be used), transferred to a Duran bottle and dissolved in $1 \mathrm{~L}$ of distilled water $\left(\mathrm{dH}_{2} \mathrm{O}\right)$. The agar mixture was autoclaved at $121^{\circ} \mathrm{C}$ for 15 minutes, poured into agar plates in a sterile laminar flow hood and left to cool and solidify. The agar plates were streaked with fungal samples obtained from Blades Biological and incubated at $25^{\circ} \mathrm{C}$ for 5-7 days.

\section{Preparation of Fungi Water Matrix}

A Sterile glass container was obtained, filled with deionised water and autoclaved at $121^{\circ} \mathrm{C}$ for 15 minutes then left to cool completely for several hours. Fungi culture of $A$. niger was inoculated in the distilled water at $25^{\circ} \mathrm{C}$ and incubated for $2,4,8$ days. 


\section{Advances in Clinical Toxicology}

\section{ROS Detection}

Intracellular ROS levels were monitored with the oxidant-sensitive probe 5-(and 6)-chloromethyl-2', $7^{\prime}$ dichlorofluorescin diacetate CM-H2DCFDA (Invitrogen). Medium $(50 \mathrm{~mL})$ was inoculated with $1 \times 10^{7}$ conidia and incubated on a rotatory shaker $(180 \mathrm{rpm})$ for 6 hours at $37^{\circ} \mathrm{C}$. The non-starved cultures were centrifuged at 4000 $\mathrm{rpm}$ and the pellet was re-suspended in $2 \mathrm{~mL}$ medium. The starved cultures were centrifuged at $4000 \mathrm{rpm}$ and the pellet was re-suspended in $2 \mathrm{~mL}$ medium without nutrition source. After starvation, the ROS assay was prepared from $20 \mu \mathrm{L}$ of either culture (starved or nonstarved) plus $180 \mu \mathrm{L}$ fresh medium or water without a nutrition source, respectively, and $2.9 \mu \mathrm{g} / \mathrm{mL} \mathrm{CM}$ H2DCFDA in a 96-well plates. The assay plate was incubated at $37{ }^{\circ} \mathrm{C}$ for 30 minutes under shaking. The arbitrary fluorescence units (AFUs) were measured at $503 \mathrm{~nm}$ of excitation and $529 \mathrm{~nm}$ of emission in the fluorimeter Synergy (Biotek) using the Gen5 software.

\section{Staining and Microscopy}

Sterile coverslips were overlaid with $5 \mathrm{~mL}$ liquid medium containing approximately $1 \times 10^{6}$ conidia and incubated at $25^{\circ} \mathrm{C}$ for 12 hours before starvation. Starvation was induced by replacing medium with distilled water and incubating at $25^{\circ} \mathrm{C}$ for different time periods. Germlings starved for 0, 2, 4, 8 day were fixed with 4\% Paraformaldehyde (PFA), and stained with TUNEL (In Situ Cell Death Detection Kit; Roche Diagnostics) for 1 hour at $37^{\circ} \mathrm{C}$, along with $100 \mathrm{ng} / \mathrm{mL}$ Hoechst 33258 (Molecular Probes), for 2 minutes and subsequently washed three times with PEM plus BSA. Hoechst double staining was performed at room temperature for 2 minutes and then washed three times for 5 minutes with phosphate buffered saline (PBS). The samples were examined using a Zeiss epi-fluorescence microscope with excitations of 359 and $563 \mathrm{~nm}$ and emissions of 461 and $582 \mathrm{~nm}$ for Hoechst and TUNEL, respectively. The phase contrast bright field and fluorescent images were captured with AxioCam camera (Carl Zeiss) and processed using the Image J software.

To determine mitochondrial mass, the strains were grown on coverslips overlaid with MitoTracker Green FM and Propidium iodide ( $2 \mathrm{mg} / \mathrm{L}$ ) staining were performed at $37^{\circ} \mathrm{C}$ for 10 minutes. The germlings were examined using a Zeiss epifluorescence microscope with MitoTracker Green FM examined under excitations of $470 / 20 \mathrm{~nm}$ and emissions of 525/50 nm; and Propidium iodide examined under excitations of $572 / 25 \mathrm{~nm}$ and emissions of $626 / 62 \mathrm{~nm}$. The phase contrast bright field and fluorescent images were captured with AxioCam camera (Carl Zeiss) and processed using the Image J software.

\section{Aspergillus niger Protein Separation Using Amicon Ultra Centrifugal Filters}

Commercially available centrifugal filtering devices, Amicon Ultra- $0.5 \mathrm{~mL}$ (Millipore-Merck, Germany), with cut-off points at $50 \mathrm{kDa}, 30 \mathrm{kDa}$ and $10 \mathrm{kDa}$, were employed in this study as examples. At first, $0.5 \mathrm{~mL}$ of fungi after 8 days starvation was placed in the $50 \mathrm{kDa}$ centrifugal filtration device, with no washing, and centrifuged at $14000 \mathrm{~g}$ for $30 \mathrm{~min}$. The filtrate obtained from the $50 \mathrm{kDa}$ device was then centrifuged using the 30 $\mathrm{kDa}$ and $10 \mathrm{kDa}$, consequently. The filter devices were then placed upside down in a new Eppendorf and spun down at $1000 \mathrm{~g}$ for $2 \mathrm{~min}$ in order to collect the remainder of the concentrate retained in the filter devices. In current study, 4 fractions were obtained; the first representing full proteins without filtration; the second corresponding to the fraction between $50 \mathrm{kDa}$ and $30 \mathrm{kDa}$ named $50 \mathrm{kDa}$ filtrate; the third corresponding to the fraction between $30 \mathrm{kDa}$ and $10 \mathrm{kDa}$ named 30 filtrate, the fourth corresponding to the fraction less than $10 \mathrm{kDa}$.

As indicated by the manufacturer, the ultrafiltration membranes in Amicon $®$ Ultra- 0.5 devices contain trace amounts of glycerine. If this material interferes with analysis, pre-rinse the device with buffer or Milli- $Q \circledR$ water. If interference continues, rinse with $0.1 \mathrm{M} \mathrm{NaOH}$ followed by a second spin of buffer or Milli-Q® water. For both washing and rinsing, $0.5 \mathrm{~mL}$ of the respective liquid was added to the filters and the centrifugation was applied for $30 \mathrm{~min}$ at $14000 \mathrm{~g}$ followed by a spinning with the devices upside down at $1000 \mathrm{~g}$ for 2 minutes in order to remove any residual solution contained in the filter. The fungi filtrates were then placed into Highperformance liquid chromatography (HPLC) to analysis the difference among different size filtrates after 8 days starvation.

\section{Reverse-Phase High-Performance Liquid Chromatography}

The mobile phase was made up of $900 \mathrm{~mL}$ of HPLC grade water and $100 \mathrm{~mL}$ of HPLC grade Acetonitrile, and was vacuum filtered using a 0.22 micron filter then sonicated for 30 minutes to remove trapped air bubbles. The solvent tube was placed into the mobile phase and the HPLC vials containing the fungi filtrates were loaded into the HPLC injection compartment. A C18 column was obtained and attached to the machine then washed by 


\section{Advances in Clinical Toxicology}

selecting needle wash, dry prime and wet prime. Each sample was run for 40 minutes and the needle washed after the last sample. The conditions were set as mentioned in the HPLC specification below. After sample analysis, the column was eluted.

The reverse-phase high-performance liquid chromatography (RP-HPLC) analysis was performed on a Waters 1525 pump (Waters, Milford, Massachusetts) with a PDA detector 2487 (Waters) using a Luna C18 column ( $5 \mu \mathrm{m}, 250 \mathrm{~mm} \times 4.6 \mathrm{~mm}$, Phenomenex). Flow rate was kept at $0.45 \mathrm{~mL} \cdot \mathrm{min}^{-1}$. The mobile phase, composed of an isocratic solution of Acetonitrile and water $(90: 10 \mathrm{v} / \mathrm{v})$, was maintained at $25^{\circ} \mathrm{C}$. The column was eluted at a flow rate of $1 \mathrm{~mL} \cdot \mathrm{min}^{-1}$ with an isocratic solvent using Methanol $(8: 2 \mathrm{v} / \mathrm{v})$ in water. Four samples, without filtration, $50 \mathrm{kDa}$ filtrate, $30 \mathrm{kDa}$ filtrate and $10 \mathrm{kDa}$ filtrate were loaded in HPLC.

\section{Controlling Protein Size by Filtration}

Samples were collected after an incubation period of 8 days at $25^{\circ} \mathrm{C}$, various filter sizes were used in order to separate the fungal proteins. The proteins were separated with Amicon ultra centrifugal filters of 50, 30 and $10 \mathrm{kDa}$. Protein samples were transferred into centrifugal filters to remove unwanted proteins and debris according to size. Four samples, without filtration, $50 \mathrm{kDa}$ filtrate, $30 \mathrm{kDa}$ filtrate and $10 \mathrm{kDa}$ filtrate were loaded on sodium dodecyl sulphate (SDS) gel to identify the protein size. A $12 \%$ separating gel was prepared by mixing $1.65 \mathrm{~mL}$ of water, $2 \mathrm{~mL}$ of $30 \%$ acrylamide mix, $1.25 \mathrm{~mL}$ of $1.5 \mathrm{M}$ Tris at $\mathrm{pH} 8.8,0.05 \mathrm{~mL}$ of $10 \%$ SDS, $0.05 \mathrm{~mL}$ of $10 \%$ ammonium persulfate and $0.008 \mathrm{~mL}$ of Tetramethylethylenediamine (TEMED); while a $4 \%$ stacking gel was made by mixing $1.4 \mathrm{~mL}$ of water, $0.33 \mathrm{~mL}$ of $30 \%$ acrylamide mix, $0.25 \mathrm{~mL}$ of $0.5 \mathrm{M}$ Tris at $\mathrm{pH} 6.8$, $0.02 \mathrm{~mL}$ of $10 \%$ SDS, $0.02 \mathrm{~mL}$ of $10 \%$ ammonium persulfate and $0.008 \mathrm{~mL}$ of TEMED. The mixture was mixed carefully and transferred using a pipette in between the gel plates, and a well comb placed on top and left to solidify. Once the gels were formed, the comb was removed; plates were placed into the electrophoresis cell and filled up with running buffer.

$100 \mathrm{~mL}$ of samples obtained from the filtrates and supernatants were collected and labelled in an Eppendorf tube. $100 \mathrm{~mL}$ of sample buffer was added to each sample and boiled for 10 minutes to denature the proteins. The protein marker was also boiled then loaded into gel wells along with each sample. The gels were run at $180 \mathrm{~V}$ between 40 to 60 minutes and stained using Coomassie brilliant blue.

\section{Western Blot}

The samples were permeabilized with $0.1 \%$ Triton X100 in PBS for 20 minutes at room temperature, equilibrated with $10 \mathrm{mM}$ glycine in PBS for 10 minutes at room temperature, then blocked in $0.1 \%$ Triton X-100, 3\% bovine serum albumin (BSA) and $0.2 \%$ goat serum in PBS for 1 hour at room temperature [23]. HSP40, PKA and Caspase 1 antibodies show immunoreactivity to HSP40, PKA and Caspase 1 -like proteins in A. niger [15,16,19]. Primary antibodies against DNAJB1 (Abcam ab69402, rabbit polyclonal anti-Hsp40, 1:100), Anti-Caspase-1 antibody (ab207802) (1:500 dilution) and Anti-(phospho T197) antibody (ab75991) (1:500 dilution) were added directly to the block and the samples were incubated overnight at $4^{\circ} \mathrm{C}$. The protein of fungi samples named 50 $\mathrm{kDa}$ filtrate were collected by filtration with filter $30 \mathrm{kDa}$ and $50 \mathrm{kDa}$ before western blot. All samples were rinsed twice quickly and 3 times for 10 minutes with PBS, then placed back in block solution containing the appropriate secondary antibodies (Donkey anti-rabbit C, whole IgG) at a dilution of 1:250. The blot was visualized with an ECL kit (Amersham-Pharmacia Biotech).

\section{Results}

\section{Fungi Growth Rate after Starvation}

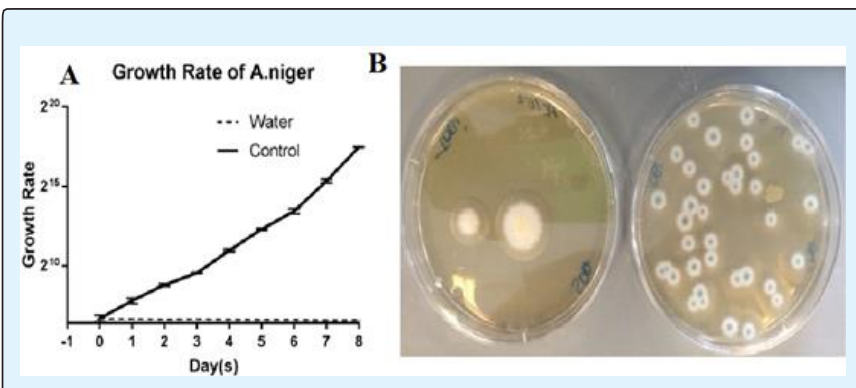

Figure 1: Growth Rate of $A$. niger over a period of 8 days starvation. (A) Fungi growth using log scale plotted over a period of 8 days. Five replicate plates were used for each time point, and the experiments were performed at least three times. Error bars show the standard deviation. (B) Left: $A$. niger cultured on SDA plate after 8 days storage in water; Right: $A$. niger cultured on SDA plate after 8 days in nutrient broth as control.

(A) Illustrates the exponential growth of Aspergillus when in nutrient broth compared to water which stays at a consistent level. 
As seen in Figure 1: (B), the fungi which incubated in water showed a decrease in growth in comparison the fungi samples obtained from the nutrient broth.

\begin{tabular}{|c|c|c|c|c|c|c|}
\hline Day(s) & \multicolumn{3}{|c|}{ Water } & \multicolumn{3}{c|}{ Control } \\
\hline 0 & 100 & 98 & 105 & 100 & 89 & 120 \\
\hline 1 & 100 & 99 & 103 & 200 & 250 & 219 \\
\hline 2 & 98 & 97 & 98 & 450 & 420 & 475 \\
\hline 3 & 99 & 98 & 99 & 760 & 750 & 735 \\
\hline 4 & 97 & 99 & 97 & 2000 & 1890 & 2130 \\
\hline 5 & 96 & 97 & 97 & 5050 & 5300 & 4890 \\
\hline 6 & 97 & 96 & 96 & 1100 & 1235 & 991 \\
\hline 7 & 96 & 94 & 94 & 4030 & 3876 & 4532 \\
\hline 8 & 94 & 96 & 95 & 18005 & 18750 & 17938 \\
\hline
\end{tabular}

Table 1: Triplicate run of growth rate of A. niger in water compared to growth medium, growth rate in water showed a steady decrease over the 8 days especially from day 4 as opposed to exponential growth observed using media.

\section{Morphology Changing under Light Microscopy}

To observe the fungi under stress, A. niger was cultured on SDA plates then transferred into sterile distilled water for a maximum of 8 days. During the first two days several conidiophores were easily visible. There was one conidiophore observed with disintegrating hyphae at day 4 . By day 8 , hyphae diameter has decreased to $10 \mu \mathrm{m}$ and has been disintegrating (Figures 2-4).
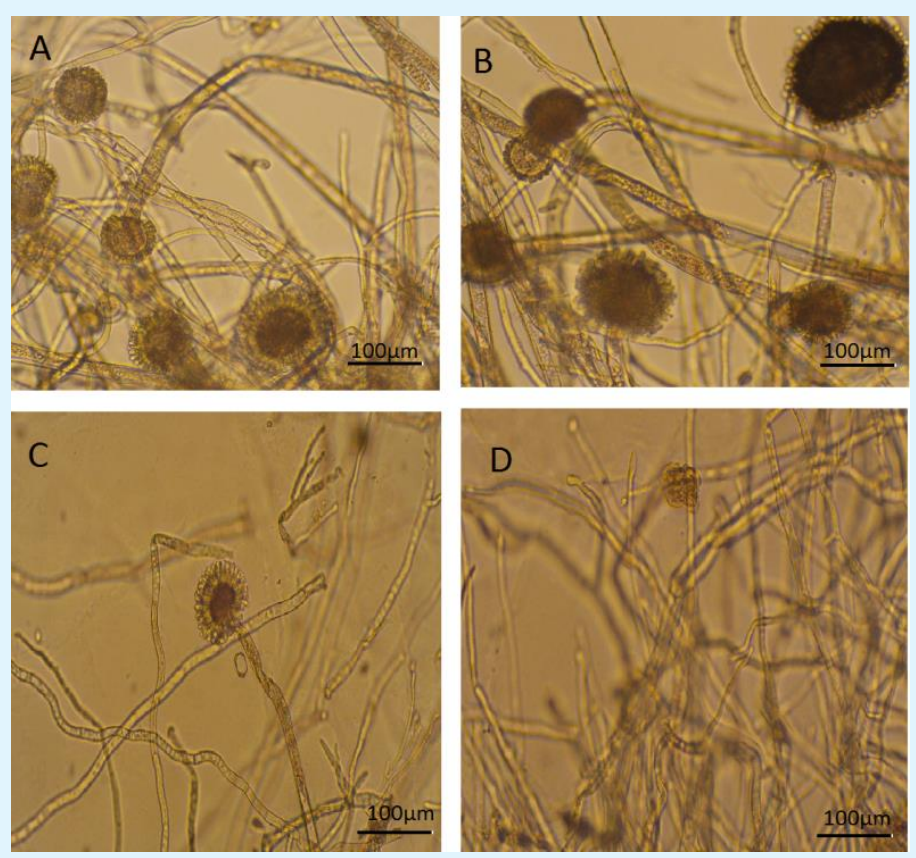

Figure 2: A. niger images observing conidiophores within a period of 8 days. A. niger structure is shown to disintegrate from lack of nutrient. (A) A. niger taken after 1 day; (B) A. niger observed after day 2; (C) A. niger observed on day 4; (D) A. niger observed on day 8. All images taken under light microscopy, using 400x microscope objective. 


\section{ROS Accumulation}

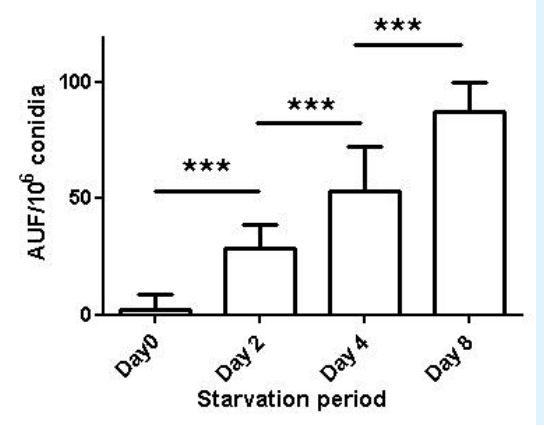

Figure 3: Starvation elevated ROS accumulation. The fluorescence density was examined to evaluate the ROS accumulation under the influence of 0-day, 2-day, 4-day and 8-day starvation, presented in the figure accordingly from left to right. The fluorescence emitted by the starving fungi of day 2 was 3.0 -fold higher than the normal ones $(\mathrm{p}<0.001)$.

\section{TUNEL Staining}

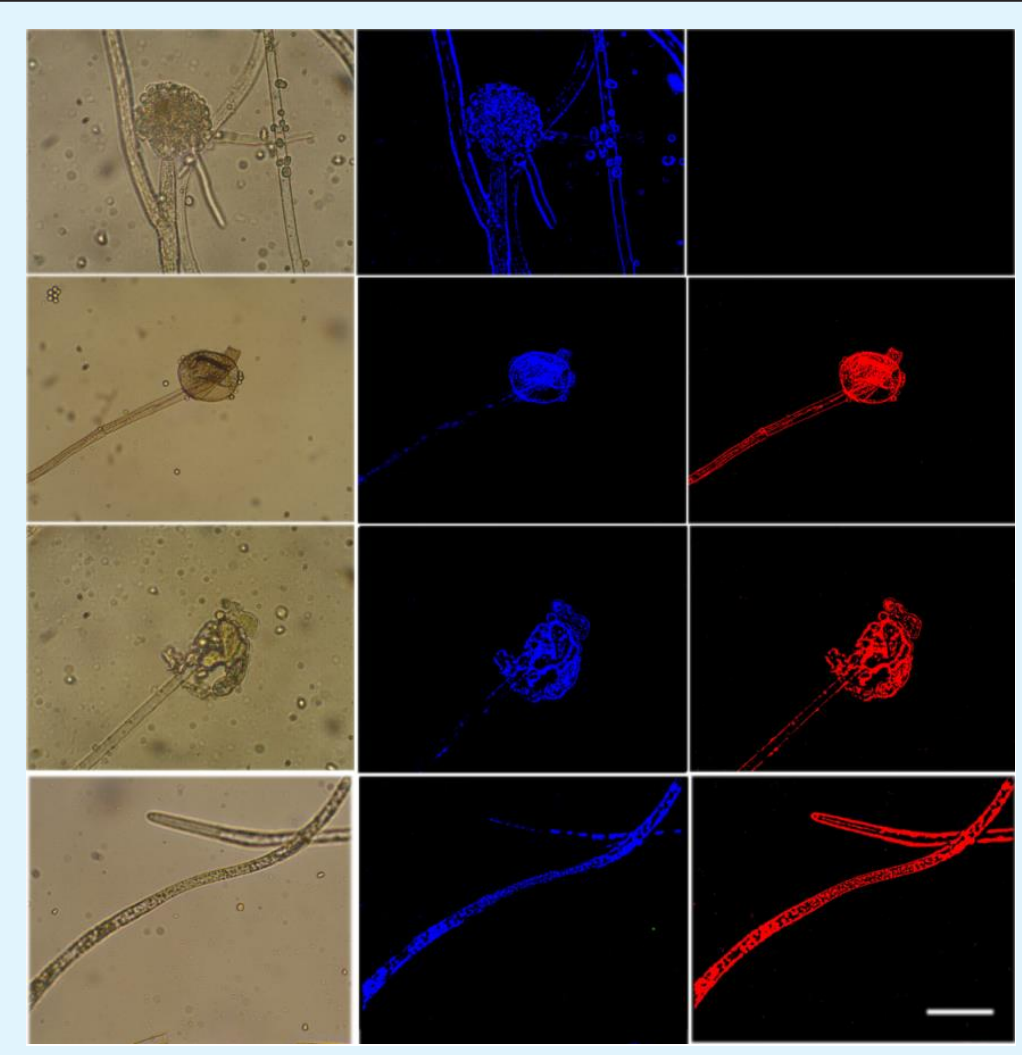

Figure 4: TUNEL assay to detect DNA fragmentation evaluating the influence of 0-day, 2-day, 4-day and 8-day starvation. Four rows from top to bottom represent day 0, day 2, day 4 and day 8, respectively. For each row, from left to right, first column presents bright field microscopy image, second column presents fluorescent microscopy image under excitations of $359 \mathrm{~nm}$ and emission of $461 \mathrm{~nm}$ for Hoechst, third column presents fluorescent microscopy image under excitations of $563 \mathrm{~nm}$ and emissions of $582 \mathrm{~nm}$ for TUNEL stain. Nuclei were visualized by Hoechst staining in blue, while TUNEL stain in red (Bars: $50 \mu \mathrm{m}$ ). 
The strain demonstrated elevated ROS accumulation in starved cells (Figure 3), which could have reflected mitochondrial dysfunction. The absence of nutrition was shown to impact mitochondrial dysfunction. Fluorescent microscopy of the mitochondrial stains, Mito Tracker Green, revealed the fluorescence emitted by the normal fungi was higher than the starving ones (Figure 5). The reduction in nutrition in the fungi was therefore attributed to a reduction in mitochondrial mass. TUNEL assay showed DNA fragmentation starting at day 2 after starvation (Figures 4 \& 5).

\section{MitoTracker Staining}

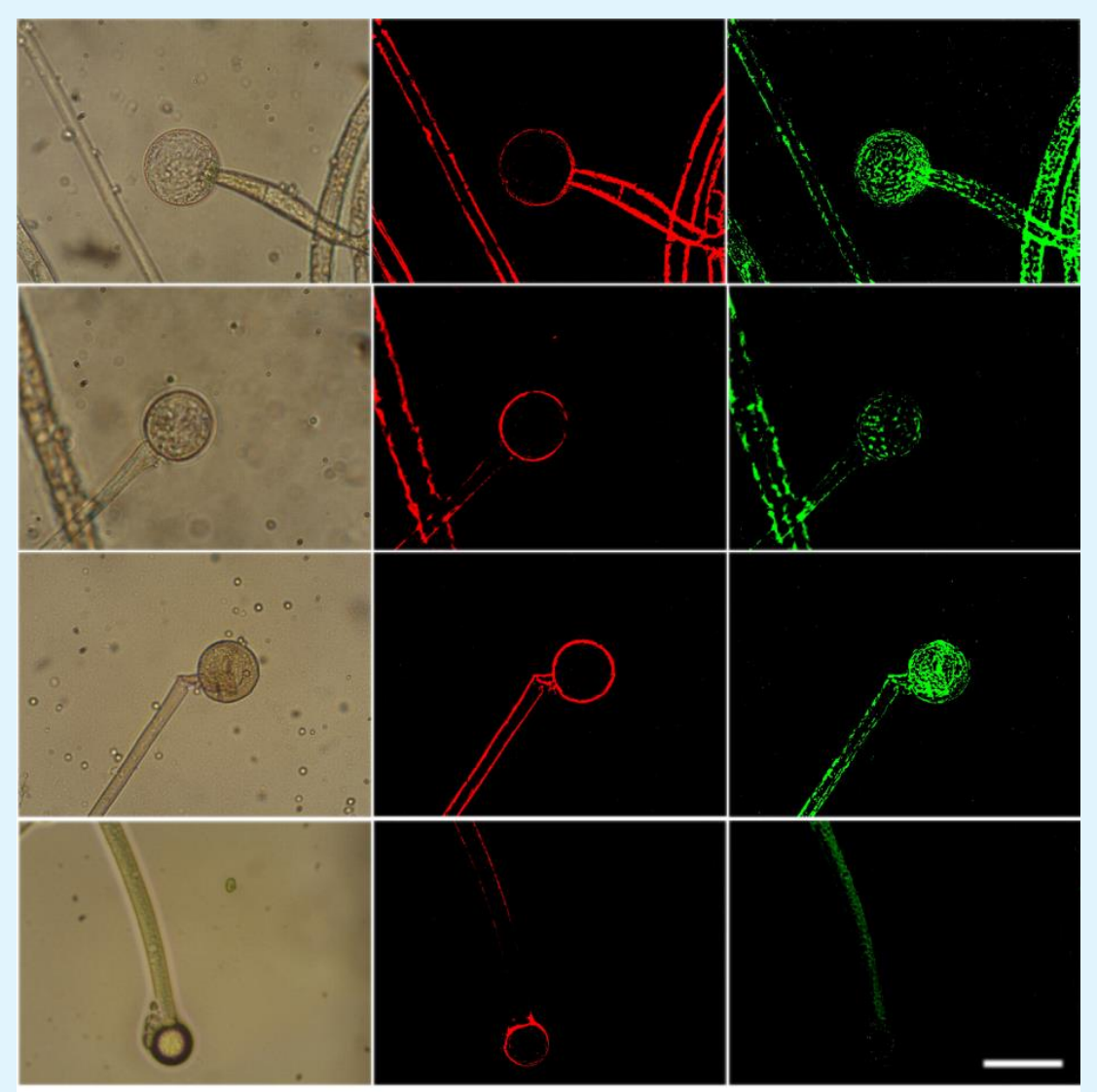

Figure 5: MitoTracker to evaluate the mitochondria activity under the influence of 0-day, 2-day, 4-day and 8-day starvation. Four rows from top to bottom represent day 0, day 2, day 4 and day 8, respectively. For each row, from left to right, first column presents bright field microscopy image, second column presents fluorescence microscope image under filters excitations of $572 / 25 \mathrm{~nm}$ and emissions of $626 / 62 \mathrm{~nm}$ for Propidium iodide, third column presents fluorescence microscope image under filters of excitations of 470/20 and emissions of 525/50 for MitoTracker. Fungi structure were visualized by Propidium iodide staining in red, and MitoTracker stain in green (Bars: $50 \mu \mathrm{m}$ ).

\section{HPLC Analysis of Different Size of Protein from Starving Aspergillus Niger}

Each sample was run against a plain sample (A) which had not undergone any filtration which acted as a standard. A. niger was shown to produce an extra peak at 3.445 minutes in the $50 \mathrm{kDa}$ filtrate. This peak at 3.445 minutes was shown in the unfiltered sample, but it was not shown in the $30 \mathrm{kDa}$ filtrate and $10 \mathrm{kDa}$ filtrate. This peak identified the bigger proteins in the sample which was eluted before 4 minutes (Figure 6). A. niger exhibited active responses to starvation such as secretion of some proteins size between 30 to $50 \mathrm{kDa}$. 

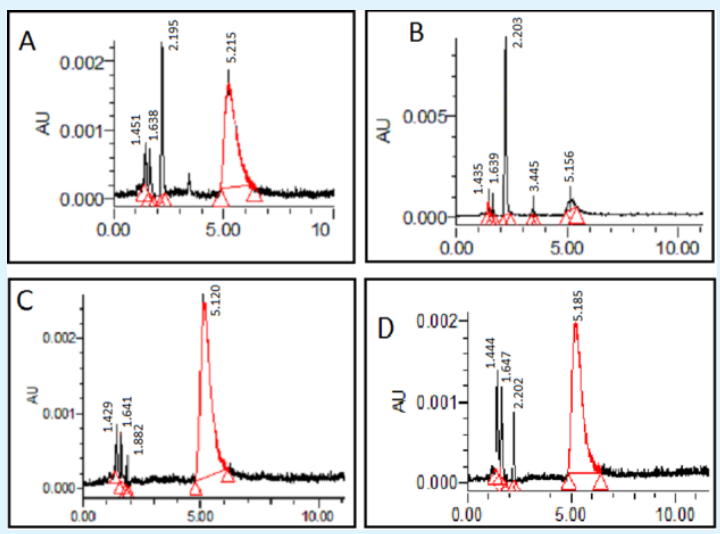

Figure 6: HPLC spectra of $A$. niger using contaminated water matrix at day 8 with (A) Non filtrated sample, (B) $50 \mathrm{kDa}$ filtrate, (C) $30 \mathrm{kDa}$ filtrate and (D) $10 \mathrm{kDa}$ filtrate sample. Analytes were detected at the wavelength of $\lambda_{\max }=210 \mathrm{~nm}$.

\section{Identify protein size by SDA page}

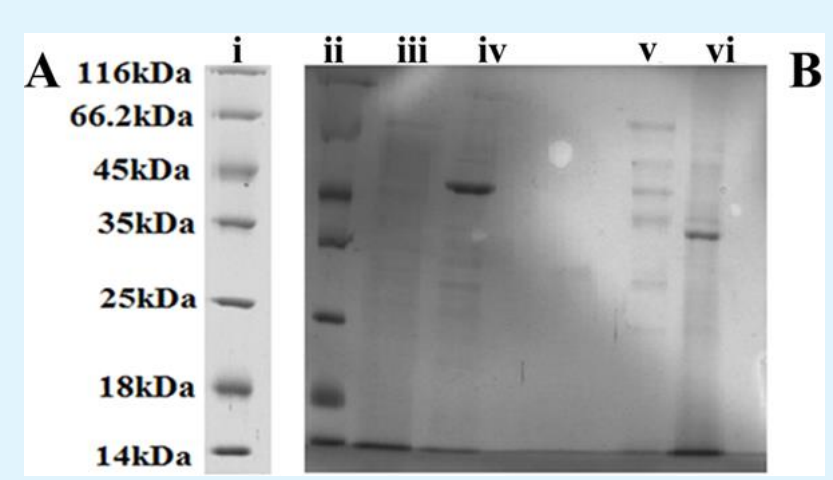

Figure 7: SDS gel composed of $12 \%$ separating gel and 4\% stacking gel. (Panel A) Protein Marker $116 \mathrm{kDa}$ to $14 \mathrm{kDa}$. (Panel B) Protein bands presented from (ii) Protein Marker, (iii) $10 \mathrm{kDa}$ filtrate, (iv) A. niger sample obtained from $50 \mathrm{kDa}$ filtrate, (v) A. niger sample without filtration, (vi) A. niger sample obtained from $30 \mathrm{kDa}$ filtrate, respectively.

Samples were collected after an incubation period of 8 days at $25{ }^{\circ} \mathrm{C}$. various filter sizes were used in order to separate the fungal proteins. Protein samples were transferred into centrifugal filters to remove unwanted proteins and debris according to size. Well IV contained from $50 \mathrm{kDa}$ filtrate, which resulted in a distinctive band around $40 \mathrm{kDa}$. Well V was loaded without filter, which showed several light bands ranging from 60 to $25 \mathrm{kDa}$. Well VI was loaded with the filtration of the $30 \mathrm{kDa}$ filter which showed a clear band at $30 \mathrm{kDa}$ (Figure 7). The proteins of size around $40 \mathrm{kDa}$ were collected from 50 $\mathrm{kDa}$ filtrate and $30 \mathrm{kDa}$ supernatant for western blot.

\section{Protein Expression on Different Protein Size and Starving Days}

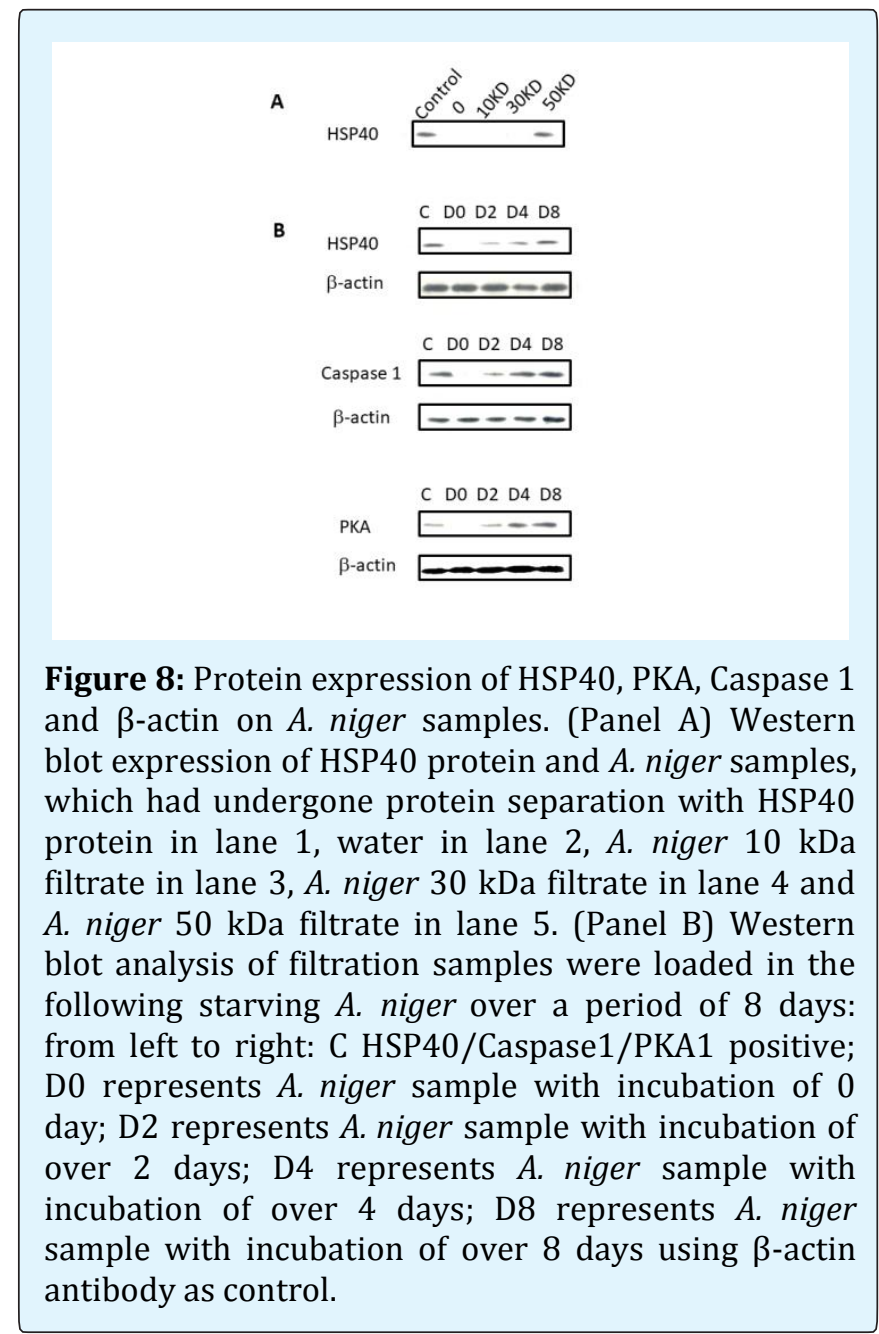

As seen in Figure 8 the HSP40 sample loaded in lane 1 and A. niger $50 \mathrm{kDa}$ filtrate and $30 \mathrm{kDa}$ supernatant was clearly visible, while there were no bands present for the $10 \mathrm{kDa}$ and $30 \mathrm{kDa}$ filtrate in lanes 2 and 3 . Once confirmed the protein of interest was observed and present in the $50 \mathrm{kDa}$ filtrate. The western blots of B panel were performed in order to study the increase in expression over the 8 days of the study. The sample was loaded onto lane 1 like the previous gel. As seen from lane 2 (Day 2), the protein expressions of HSP40, PKA and 
Caspase 1 were a steady increase shown with intensity and band thickness across day 4 to day 8 , and the longer the incubation period, the more increase in protein. As shown in Figure 8 the samples were properly dispersed in the wells, and there was a noticeable increase shown by the thickness of the bands on days 4 and 8 in comparison to day 2 .

\section{Discussion}

Managing changes in water balance is a fundamental challenge for fungi in most environments. For survival of yeasts and fungi, starvation has been shown to depend on the nature of the missing nutrients. Generally, starvation in natural nutrients such as carbon, phosphate and nitrogen results in low death rates in comparison to starvation from amino acids or other metabolites. Here we study the effect of stress and starvation in A. niger regarding to growth and appearance under light microscopy over a period of 8 days. By comparing the growth rate of $A$. niger in water to growth in medium, growth rate in water exhibits a steady decrease over the 8 days especially from day 4 as opposed to exponential growth observed using media (Figure 1, Table 1). Visual representation views the change in structure and growth under light microscopy. There are visible conidiophores during the first two days. There is one conidiophore observed with disintegrating hyphae at day 4 . By day 8 , hyphae exhibit decreased to $10 \mu \mathrm{m}$ in diameter and have been disintegrating (Figure 2).

ROS acts as signalling molecules and cellular toxicants. Mitochondrial dysfunction or the impairment of oxidative phosphorylation results in ROS accumulation [24]. A shift in the balance between oxidants/antioxidants in the direction of oxidation contributes to the induction of apoptosis [25,26]. After stress, high levels of $\mathrm{p} 40$ lead to a shift in oxidant/antioxidant balance, which can result in apoptotic cell death. Therefore, the starvation results in ROS-mediated cell death. This concept is supported by the observed increasing ROS accumulation in starved cells (Figure 3). Mitochondria are crucial to metabolism, cellcycle progression, signalling, and apoptosis. The increasing ROS accumulation could have reflected mitochondrial dysfunction. The absence of nutrition has been shown to impact mitochondrial dysfunction. Fluorescent microscopy of the mitochondrial stains, Mitotracker Green, reveals the fluorescence emitted by the normal fungi was higher than the starving ones (Figure 5). The reduction in nutrition in the fungi is therefore attributed to a reduction in mitochondrial mass. TUNEL assay shows that DNA fragmentation started at day 2 after starvation (Figure 4). The mitochondria leads to inefficient respiration and energy metabolism plus the increased generation of free radicals that are able to create life-threatening DNA lesions [27].

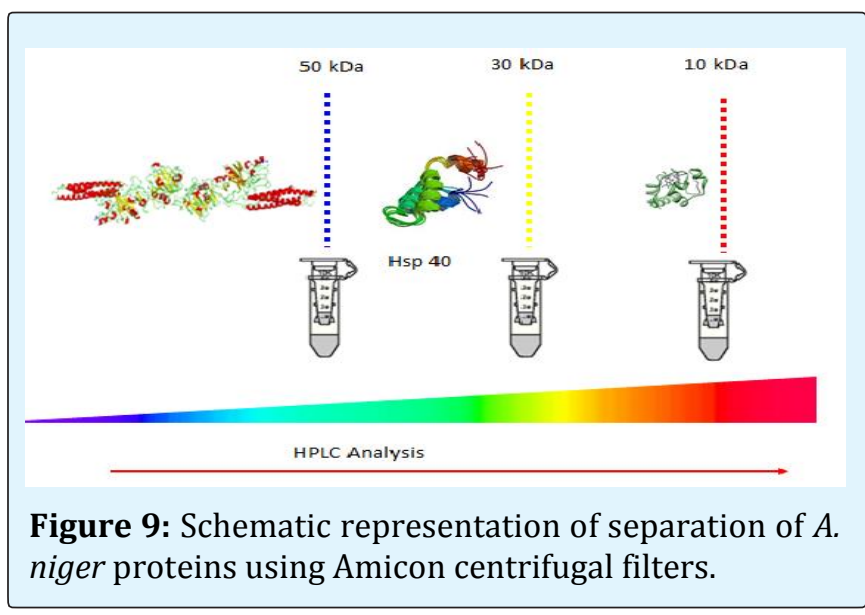

Protein samples can be transferred into centrifugal filters to remove unwanted proteins and debris according to size. Filtration with $50 \mathrm{kDa}$ and $30 \mathrm{kDa}$ can remove big molecular and small protein to separate protein at size range from 30 to $50 \mathrm{kDa}$ (Figure 9). The proteins size from $30 \mathrm{kDa}$ to $50 \mathrm{kDa}$ act different as other size protein under HPLC (Figure 7). SDS page confirms that A. niger actively responses to starvation such as secretion of some $40 \mathrm{kDa}$ proteins to manage changes in water balance from lack of nutrient (Figure 7).

In human cell, Caspase- 1 plays a prominent role in inflammatory responses and the regulation of apoptosis of various tumour cells $[10,11]$. The caspase-like proteins have been found in C. elegans, Drosophila, zebrafish and mammals to involve apoptosis [16]. A caspaseindependent pathway also exists in fungi, which (similar to situation in human) involves mitochondrion-associated cell death. In the filamentous fungus Aspergillus fumigatus, apoptotic-like cell death occurring after exhaustion of the carbon source and entry into the stationary phase of growth is associated with intracellular activity against caspase- 1 and -8 substrates and is blocked by the pancaspase inhibitor [15]. Increased PKA led to inflammation-independent activation of caspase- 1 . Starvation increases fungi stress. Stress terms are linked to fungal stress response protein HSP40 [27,28]. Starvation can induce up-regulation expression of cell cycle-associated proteins such as PKA, Caspase 1 and HSP40. 
Starvation could cause cell number reduction (Figure 2) and hype disintegrating and further decrease in mitochondria function, DNA damage. These results suggest that up regulation of apoptosis-associated protein may contribute to fungi apoptosis. In conclusion, starvations can active PKA, Caspase 1 and HSP40 protein to inhibit $A$. niger growth by inducing cell apoptosis.

\section{Conclusion}

Fungi species is the major influencing factor in the starvation, due to lack of nutrition. In current study, it has been found starvation can inhibit $A$. niger survival rate and can cause conidiophores disintegrate in a timedependent manner. The increasing ROS accumulation and reduction in mitochondrial mass increase generation of free radicals that is able to create life-threatening DNA lesions. The protein sized were successfully separated with 10, 30, $50 \mathrm{kDa}$ filters. The responsible of different size of protein were analysed by HPLC. The accurate size of active protein was identified by SDS page. Three kinds of protein, such as, PKA, Caspase 1 and HSP40 with size rang at $40 \mathrm{kDa}$ were examined under Western Blot to investigate the protein expression after starvation. Protein size from 30 to $50 \mathrm{kDa}$ appears more sensitive due to starvation. A. niger exhibits active responses to starvation such as secretion of some $40 \mathrm{kDa}$ proteins to manage changes in water balance. Starvation increases fungal stress response protein HSP40. Increased PKA can active caspase-1. Starvation can induce up-regulation expression of cell cycle-associated proteins such as PKA, Caspase 1 and HSP40. Starvation cans active PKA, Caspase 1 and HSP40 protein to inhibit A. niger growth by inducing cell apoptosis.

\section{Conflicts of Interest}

There is no conflict of interest.

\section{Acknowledgements}

T. S. and K.L. thanks Fiosraigh Scholarship Programme from Dublin Institute Technology. This work is supported by National Natural Scientific Fund (No.81225010), 863 Project of China (2014AA020700), Shanghai Science and Technology Fund (No.13NM1401500), Shanghai Jiao Tong University Innovation Fund for Postgraduates (No. AE340011).

\section{References}

1. Graciele KN, Lausser A, Juranic M, Dresselhaus T (2012) Egg cell signaling by the secreted peptide ZmEAL1 controls antipodal cell fate. Dev cell 23(1): 219-25.

2. Yule L, Schiff M, Kirk Tallóczy CZ, Levine B, DineshKumar SP (2005) Autophagy regulates programmed cell death during the plant innate immune response. Cell 121(4): 567-577.

3. Andreas S, Liam O'Connor, Dixit VM (2000) Apoptosis signalling. Annual review of biochemistry 69: 217245.

4. Scott HK, Hengartner MO (2001) Programmed cell death: alive and well in the new millennium. Trends in cell biology 11(12): 526-534.

5. Lois KM (1997) Baculovirus interaction with host apoptotic pathways. Journal of cellular physiology 173(2): 178-182.

6. Mark MM, Stanfield GM, Horvitz HR (1998) Genetics of programmed cell death in C. elegans: past, present and future. Trends in genetics 14(10): 410-416.

7. Eric L, Kato N, Lawton M (2001) Programmed cell death, mitochondria and the plant hypersensitive response. Nature 411(6839): 848-853.

8. Kai-Uwe F, Madeo F (2000) Apoptosis in yeast-a monocellular organism exhibits altruistic behaviour. FEBS letters 473(1): 6-9.

9. Frank M, Engelhardt S, Herker E, Lehmann N, Maldener C, et al. (2002) Apoptosis in yeast: a new model system with applications in cell biology and medicine. Current genetics 41(4): 208-216.

10. Paul GB, Butt VS, Davies DR, Zimmerlin A (1995) The origin of the oxidative burst in plants. Free radical research 23(6): 517-532.

11. Karen EI, Forman HJ (2002) Macrophage signalling and respiratory burst. Immunologic research 26(1-3): 95-105.

12. Heinz DO (1990) Molecular analysis of aging processes in fungi. Mutation Research/DNAging 237: 1-8. 
13. Andrea H, Brust D, Heinz DO (2008) Apoptosis pathways in fungal growth, development and ageing. Trends in microbiology 16(6): 276-283.

14. Anthony GU, Karen O'Rourke, L Aravind, Pisabarro MT, Seshagiri S, et al. (2000) Identification of paracaspases and metacaspases: two ancient families of caspase-like proteins, one of which plays a key role in MALT lymphoma. Molecular cell 6(4): 961-967.

15. Amin AMS, Robson GD (2004) Oxidative and amphotericin B-mediated cell death in the opportunistic pathogen Aspergillus fumigatus is associated with an apoptotic-like phenotype. Microbiology 150(6): 1937-1945.

16. Neta S, Goldfinger N, Sharon A (2012) Apoptotic-like programed cell death in fungi: the benefits in filamentous species. Front oncol 2: 97.

17. Camile PS, Hornby JM, Dumitru R, Nickerson KW, Harris SD (2006) Farnesol-induced apoptosis in Aspergillus nidulans reveals a possible mechanism for antagonistic interactions between fungi. Molecular microbiology 59(3): 753-764.

18. Jijun C, Park TS, Chio LC, Fischl AS, Ye XS (2003) Induction of apoptosis by sphingoid long-chain bases in Aspergillus nidulans. Molecular and cellular biology 23(1): 163-177.

19. Eva L, Szappanos H, Oberparleiter C, Kaiserer L, Csernoch L, et al. (2005) Antifungal protein PAF severely affects the integrity of the plasma membrane of Aspergillus nidulans and induces an apoptosis-like phenotype. Antimicrobial agents and chemotherapy 49(6): 2445-2453.

20. Talaska FF, Dunning MB (2009) A manual of laboratory and diagnostic tests (Lippincott Williams \& Wilkins), pp: 1317.

21. Kangze L, Zhonglei He, Byrne H, Curtin J, Tian F (2018) Investigating the Role of Gold Nanoparticle
Shape and Size in Their Toxicities to Fungi. Int J Environ Res Public Health 15(5): 998.

22. Tobiloba S, Conde J, Liu K, Curtin J, Byrne HJ, et al. (2017) Plasmonic gold nanoparticles for detection of fungi and human cutaneous fungal infections. Anal bioanal chem 409(19): 4647-4658.

23. Furong T, Nakahara T, Yoshida M, Honda N, Hirose $H$, et al. (2002) Exposure to power frequency magnetic fields suppresses X-ray-induced apoptosis transiently in Ku80-deficient xrs5 cells. Biochem Biophys Res Commun 292(2): 355-361.

24. Emilia P, Nadella K, Towns WH, Lawrence S (2008) Mutation of Prkar1a causes osteoblast neoplasia driven by dysregulation of protein kinase $\mathrm{A}$. Molecular Endocrinology 22(2): 430-440.

25. Man TK, Starost MF, Nesterova M, Boikos SA, Watkins T, et al. (2010) Alternate protein kinase A activity identifies a unique population of stromal cells in adult bone. Proc Natl Acad Sci 107(19): 8683-8688.

26. Chirathivat HS, Namde M, Dwyer A, Poznanski A, Canna S, et al. (2007) Arthropathy of neonatal onset multisystem inflammatory disease (NOMID/CINCA). Pediatr radiolo 37(2): 145-152.

27. Ivona A, Nowak M, Mallah M, Chae JJ, Watford WT, et al. (2002) De novo CIAS1 mutations, cytokine activation, and evidence for genetic heterogeneity in patients with neonatal-onset multisystem inflammatory disease (NOMID): a new member of the expanding family of pyrin-associated autoinflammatory diseases. Arthritis \& Rheumatism 46(12): 3340-3348.

28. Virginie P, Dostert C, Muruve DA, Tschopp J (2007) The inflammasome: a danger sensing complex triggering innate immunity. Current opinion in immunology 19(6): 615-622. 